\title{
History of surgery for the correction of spinal deformity
}

\author{
Avinash Lalith Mohan, M.D., AND Kaushik Das, M.D. \\ Department of Neurosurgery New York Medical College, Valhalla and New York, New York
}

\begin{abstract}
During the last century the technological advances in the field of spinal surgery had a dramatic impact on the treatment of spinal deformity in children and adults. Before the advent of medications and vaccines to treat and/or prevent tuberculosis and poliomyelitis, patients suffering from these disorders often became incapacitated by the resulting kyphoscoliosis. In the early 1900 s Lange began to address this problem mechanically by using foreign materials to stabilize the spine internally. In the 1950s and 1960s, owing to the efforts of Harrington and others, the process evolved to create the first generation of modern spinal instrumentation. The Harrington rod was able to correct a spinal deformity primarily through distraction. In the next wave of advances, some of the shortcomings of Harrington rods were addressed. Segmental fixation involving sublaminar wires was introduced in the 1970s by Luque. Anterior approaches and instrumentation-related techniques developed by Zielke and colleagues as well as Dywer and coworkers in the late 1960s and mid-1970s allowed for better correction of deformity with immobilization of fewer motion segments compared with posterior surgery. Transpedicular fixation of the spine was popularized by Cotrel and Dubousset in the 1980s; they used the technique to perform segmental stabilization, which better reduces the rotational aspect of a deformity. Finally, in the mid-1990s, thoracoscopic techniques were developed and are currently in use for anterior release and placement of instrumentation. The authors review the major technical developments for the surgical treatment of spinal deformity.
\end{abstract}

KEY WORDS • spinal deformity • historical review - scoliosis

The surgical management of spinal deformity has always been a challenging and complex problem. Throughout the 20th century, numerous surgery-related innovations were developed to correct this disorder effectively. Current instrumentation used to treat degenerative and traumatic spinal conditions was largely developed for the management of spinal deformity.

\section{EARLY HISTORY OF PROCEDURES TO CORRECT SPINAL DEFORMITY}

Early attempts to correct spinal deformity were largely nonsurgical and involved the use of external braces, traction, and casts. One unsuccessful surgical approach introduced by Jules Guerin in 1839 involved percutaneous vasotomies of the vertebral musculature with postoperative brace therapy. ${ }^{24}$ Only in the late 19 th century did surgeons begin to devise effective methods for correcting the deformed spine internally.

In 1891, Hadra attempted wiring of the spinous processes in a patient with progressive deformity due to Pott disease and successfully stabilized the spinal fracture. ${ }^{9}$ In 1911 Hibbs introduced the concept of noninstrumenta-

Abbreviations used in this paper: $\mathrm{CD}=$ Cotrel-Dubousset; USS = Universal Spine System; VB = vertebral body. tion-induced osseous fusion for stabilization of a deformed spine. ${ }^{13,25}$ Although this procedure initially provided stabilization, it relied heavily on the use of casts and did not ultimately provide deformity correction.

Until the advent of antibiotic agents to treat tuberculosis and the discovery of a vaccine to eradicate polio, large populations of patients suffered from these disorders. With little or no effective medical therapy, patients with long-standing disease often developed spondylitis and subsequent kyphoscoliosis. In patients with polio, the severe spinal deformities frequently led to cardiopulmonary compromise and death. Patients were placed in various types of braces or contoured plaster casts to halt the progression of the spinal deformity, but these treatments were often ineffective. Prior to the 20th century, it was believed that scoliosis, regardless of origin, was caused by poor posture. Thus, most attempts to resolve this deformity were aimed at correcting posture. Methods included extending the spine through an external axial distraction device, applying vests and casts to mold a correct curvature for the spine, or using braces. ${ }^{14,26}$

Fritz Lange, ${ }^{17}$ who treated patients with tuberculous spondylitis in the early 1900 s, was one of the first physicians to use foreign materials such as silk or metal to supplement and return function to parts of the human body. He thought that parts of the body that had a purely mechanical function could be replaced, including those 
involved in movement and support. He hypothesized that since orthopedic surgeons used splints to support long bone fractures, such a method might be successfully applied to correct the deformed or spondylotic spine. External splints for the deformed spine, he found, were inadequate, and he began to perform surgery to splint the spine internally by using an "artificial spinal column of steel."17 In this procedure 4-mm-thick steel wires, one on each side of the spinous processes, were placed under the muscles and fastened using silver wires from above and below. This method, however, led to infection and irritation from the wires' sharp edges. Lange began research in animals to determine an appropriate metal that would reduce these two complications. In 1908, he again tried using steel wires, this time $5-\mathrm{mm}$ thick and $10-\mathrm{cm}$ long, coated with tin, and with tin knobs on either end to reduce irritation; he fastened these to the spinous processes by using paraffin-sublimate silk. Postoperatively, the patient was kept in a plaster-of-paris jacket for as long as 6 weeks and then was slowly mobilized. He found that internal fixation induced faster healing than brace therapy alone. Although he was successful with a small number of patients, the goal of surgical treatment at this time was halting the progression of deformity rather than correcting it.

\section{MODERN ERA OF SPINAL INSTRUMENTATION}

Major developments in correcting the deformed spine did not occur until Harrington addressed the problem of the spondylitic spine in patients with poliomyelitis. These patients often suffered from much pain due to the changed curvature of their spine. Poliomyelitis had again achieved epidemic proportions in the 1940s, leaving patients with debilitating spinal deformities. These patients were frequently treated at Jefferson Davis City-County Hospital, where Harrington worked (Fig. 1). Polio-related trunk involvement often led to scoliosis and cardiopulmonary compromise. The placement of inadequate casts or the

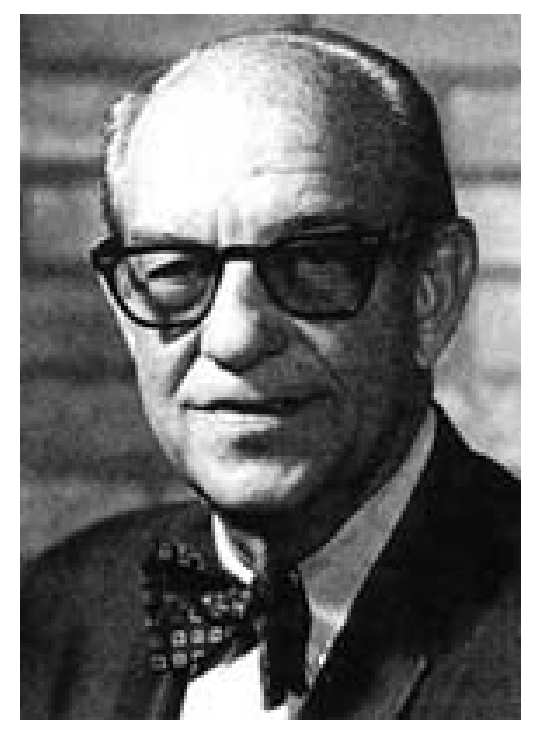

Fig. 1. Photograph of Paul R. Harrington. From Harrington, 1988; reprinted with permission from Lippincott. undertaking of major surgery usually yielded catastrophic results. Harrington ${ }^{12}$ initially tried to correct the scoliotic curvature by correcting the position of the facet joints by using screws. The initial results were encouraging, but the long-term results were poor. ${ }^{11}$ During this period techniques advanced from the use of facet screws alone, to the placement of hooks on posterior elements, to the use of combinations of hooks and rods made of stainless steel. Harrington hand made the early instrumentation. When the metal instrumentation failed over the long term, he worked with engineers to develop metals that could undergo more repetitive stress. He also decided to use concurrent fusion techniques with bone graft to supplement fixation strength. In this way patients required fewer days of postoperative immobilization. Although initially used to treat patients with polio-related deformity, these procedures were then used to treat idiopathic scoliosis as well. Harrington began teaching his technique at other institutions. As it became more widely used, broader applications followed. Through the efforts of Harrington, ${ }^{10,11}$ Moe alone $^{22}$ and with coworkers ${ }^{23}$ and others, ${ }^{8,16,17}$ the procedure was used to test other causes of spinal deformity, including traumatic fractures, spondylolisthesis, and idiopathic scoliosis..$^{28}$ The idea of using internal stabilization to correct a spinal deformity marks the beginning of the modern era of spinal instrumentation.

The Harrington procedure was refined by the 1970s. The new technique consisted of hooks applied to both the cranial and caudal ends of a deformity; the hooks were then attached to rods ${ }^{6,12}$ (Fig. 2). Distraction was used to reduce the deformity. This was then followed by an osseous fusion. This was clearly the first attempt to correct spinal deformity surgically rather than merely provide stabilization. The technique was used successfully to treat hundreds of patients with idiopathic, neuromuscular, and acquired scoliosis. As longer follow-up data became

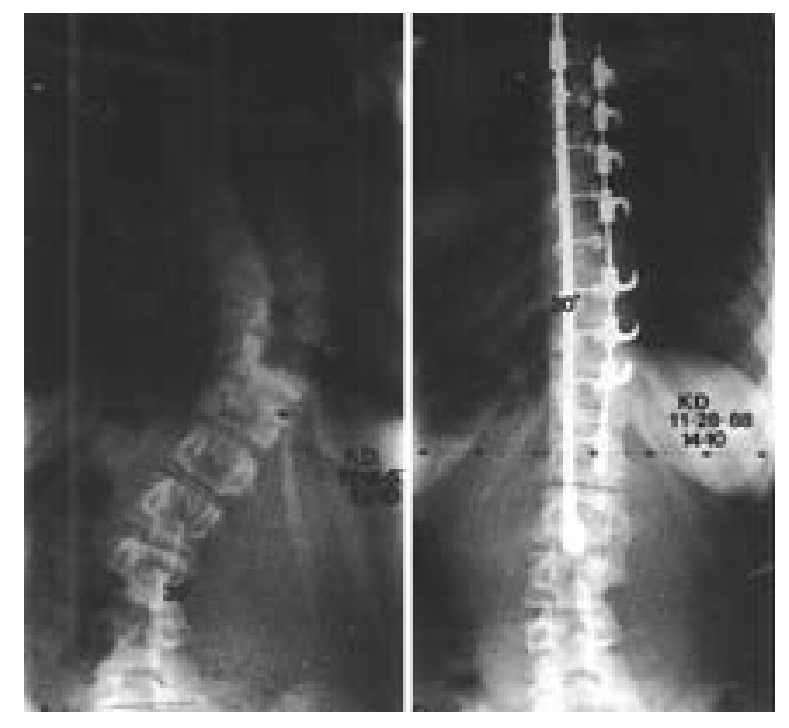

Fig. 2. Preoperative (A) and postoperative (B) radiographs obtained in a patient with kyphoscoliosis. Posterior Harrington rod instrumentation was placed in the thoracolumbar spine. From Winter and Lonstein, 1992; reprinted with permission from Elsevier Science. 
available, several problems became apparent. In Harrington's system, because only posterior instrumentation was applied, a long construct without segmental fixation was required. This led occasionally to loosening of the instrumentation, and a reoperation was required to remove the rods after the segments were fused. It often involved fusion down to the sacrum, which led to the loss of lumbar lordosis and flat-back syndrome. These disadvantages provided the impetus for the next wave of changes.

In 1976, Luque ${ }^{20}$ instrumentation was introduced for posterior segmental fixation of the spine. This procedure involved multiple points of fixation by using sublaminar wires to create a more biomechanically sound construct. The goal was to reduce the need for external immobilization. Segmental instrumentation involved steel wire loops that were placed under the lamina at various levels and over prebent rods ${ }^{20}$ (Fig. 3). Although this technique was an improvement, it still failed to address some of the problems inherent to a long posterior construct. In addition, a significant incidence of neurological complications was demonstrated. ${ }^{27}$

Correction and stabilization of scoliotic deformity via an anterior approach was also introduced in the 1970s. This was a major advance in the field of spinal deformity surgery. The anterior approach allowed for the placement of shorter constructs and better correction of the deformity. Dwyer, et al., ${ }^{7}$ reported using anterior instrumentation. They believed that scoliotic deformities could be approached in two ways, either by stretching the concave side of the curved column or by shortening the long convex side. Titanium screws were inserted into the VB on the convex side. With the aid of plates over these screws,

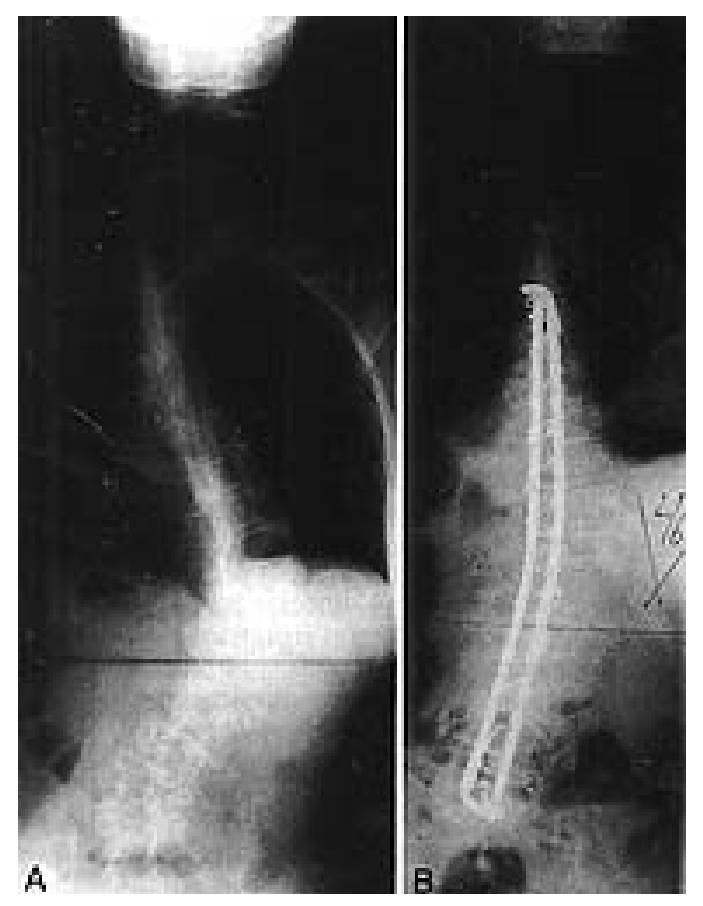

Fig. 3. Preoperative (A) and postoperative images (B) obtained in a patient with kyphoscoliosis. Posterior Luque rod instrumentation that was placed in the thoracolumbar spine. From Kostuik, 1992; reprinted with permission from Elsevier Science.

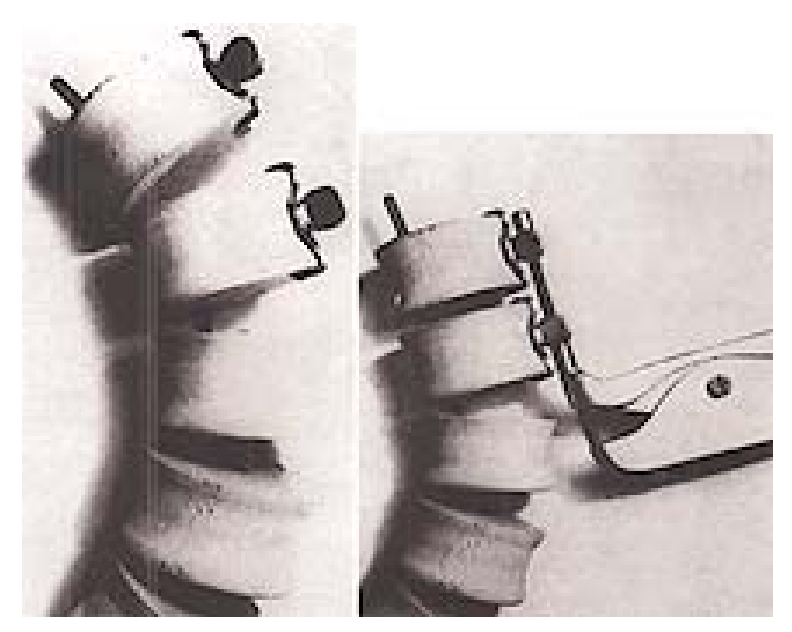

Fig. 4. Photographs demonstrating the Dwyer technique for distraction of the spine via an anterior approach. From Dwyer, et al., 1969; reprinted with permission from Lippincott.

a titanium cable is threaded through the screw heads, and the distance is shortened between the screws by a tensioning device (Fig. 4). By continuing this process down each level of the spine, a bent column would become straighter. Their patients wore a jacket to restrict movement for up to 3 months postoperatively.

The development of Zielke instrumentation resulted in greater correction of deformities than previous techniques. ${ }^{29}$ This method improved on the Dwyer technique by requiring that the VB screws be placed more posteriorly (Fig. 5) to enhance the derotation effect and reduce the incidence of iatrogenic kyphosis. ${ }^{24}$ Because anterior techniques do not allow for immobilization and fusion of as many segments as posterior techniques, the incidence of flatback deformity is reduced.

Although excellent correction of deformity was possible via the anterior approach, significant incidences of pseudoarthrosis, hardware failure, and loss of correction with the single rod technique remained. ${ }^{15}$ In an attempt to overcome these shortcomings, next-generation anterior

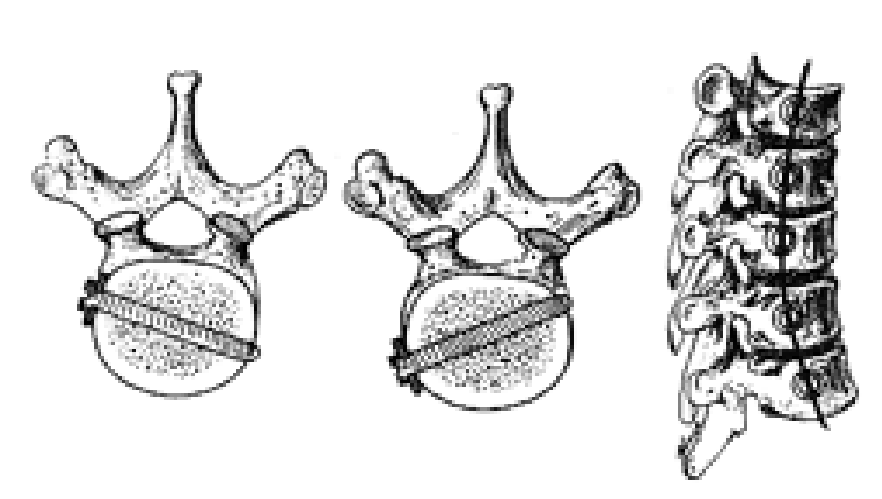

Fig. 5. Drawings demonstrating the Zielke method for anterior instrumentation and VB screw placement in a scoliotic curve. Left: Screw placement from the convex to the concave side. Center: Screw placement for a hyperlordotic curve. Right: Lateral view of screw placement. From Moe, et al., 1983; reprinted with permission from Lippincott. 
instrumentation, which involves a dual-rod technique, was introduced. The Kaneda system involves the placement of two screws in each VB that are attached to two rods; this system allows for better derotation and creates a biomechanically stronger construct (Fig. 6). Anterior approaches are useful for thoracolumbar curves down to L-5 but cannot be used alone if there is a significant thoracic kyphosis.

The next major advance was the development of transpedicular fixation of the thoracolumbar spine. Biomechanically, pedicle screws are superior to other posterior materials (that is, hooks and sublaminar wires) with respect to pullout strength and load-bearing capacity. ${ }^{4}$ They provide three-column fixation of the spine, which can be used to rotate, distract, or compress motion segments prior to fusion. The CD fixation system was introduced in the 1980s. ${ }^{1}$ In this system the goal was to combine the rigidity of segmental fixation with curve derotation to obtain correction. All three elements of instrumentation-hooks, rods, and screws - were used. The hardware consists of posterior instrumentation with 7-mm rods, a series of pedicular and laminar hooks that can be secured to the rod at any point along its length and in any transverse axis of rotation, and transverse approximators. ${ }^{3}$ The CD allows for distraction, compression, and derotation of the scoliotic deformity. ${ }^{1}$ In the initial study of patients with idiopathic scoliosis treated with the CD system, significant reduction of their curvature was achieved. ${ }^{3}$

Further experience with the CD system showed that derotation of the scoliotic spine by rotation of the rod does not always fully correct the deformity. In addition, the spine can become unbalanced above and below the construct. These shortcomings led to the development of a

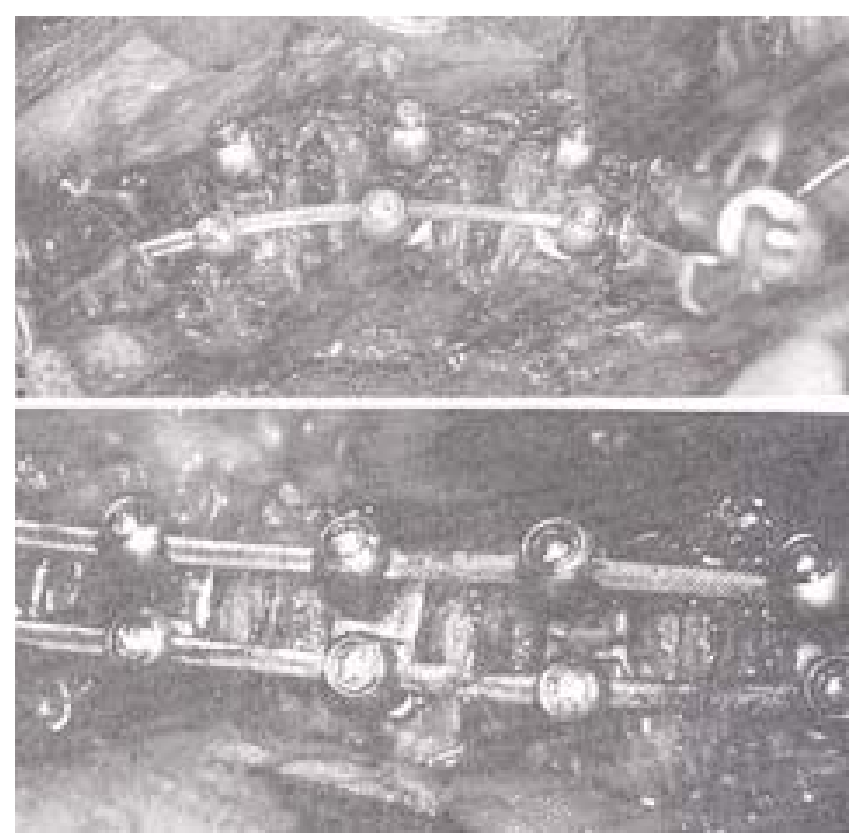

Fig. 6. Photographs demonstrating the derotation maneuver of the Kaneda two-rod system. Upper: Before derotation. Lower: Completion of derotation. From Kaneda, et al., 1996; reprinted with permission from Lippincott-Raven.

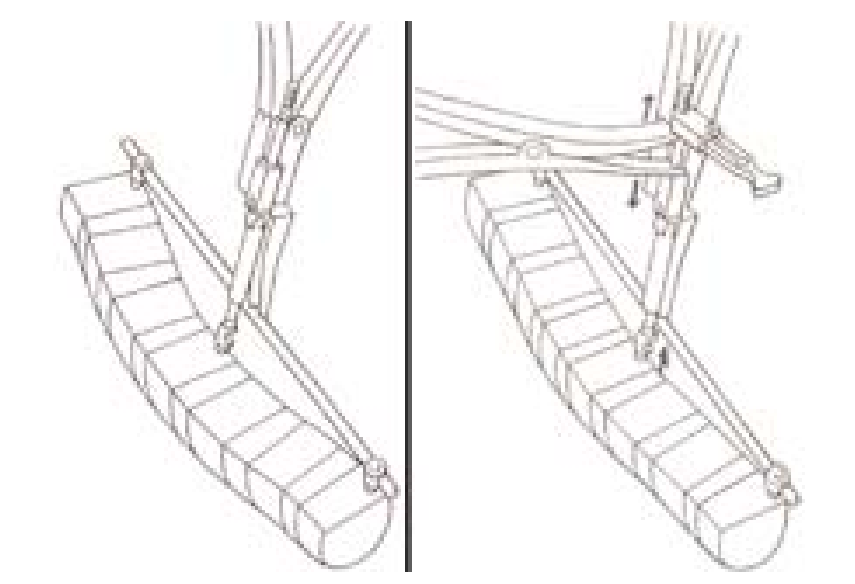

Fig. 7. Drawing showing the USS hardware. Left: Prior to reduction, the USS reduction forceps, attached to the hook, are placed on the rod. Right: Postreduction, the forceps are shown attached to the hook and placed on the rod. From AO ASIF Principles in Spine Surgery, Aebi, et al., p 139, 1998; reprinted with permission from Springer-Verlag.

newer generation of pedicle screws and hooks. The USS was designed so that the cranial and caudal ends of the construct are rigidly fixed to two rods to create a frame. ${ }^{18}$ The screws are placed in the most caudal and cranial segments of the deformity, and a rod is placed between them to create a frame. Instrumentation is then placed in each intervening vertebral segment, and the VBs are rotated and/or translated into the frame (Fig. 7). Recently, thoracic pedicle screws have been used as an alternative to hooks. They provide better anchor points, and the authors of clinical studies have shown that more effective curve correction can be achieved using these devices than with hooks. ${ }^{19}$ The Texas Scottish Rite Hospital instrumentation system involves principles of correction similar to those of the USS but also has side-loading connectors that make revision surgery easier. ${ }^{2}$ The latest generation of pedicle screws have polyaxial heads that facilitate rod placement in cases in which the pedicles are not well aligned (Fig. 8).

In the 1990s further developments in the fields of surgical endoscopy led to the application of thoracoscopy to spinal surgery. ${ }^{5}$ Video-assisted thoracoscopy has been used to perform anterior release as well as anterior fusion and stabilization in cases of spinal deformity. ${ }^{21}$ Morbidity seems to be reduced with this approach. Further studies are necessary to validate the effectiveness of this newer technology.

\section{CONCLUSIONS}

Advancements in the field of spinal deformity surgery have improved the quality of life of many patients. Over the course of the 20th century, antibiotic agents reduced the incidence of tuberculosis and vaccines have virtually eliminated polio. The late-stage deformities secondary to these conditions are hardly seen by the present-day spine surgeon. The problems initially addressed by spine surgeons, such as the complexity of kyphoscoliosis, however, remain. The goals of current and future minimally inva- 


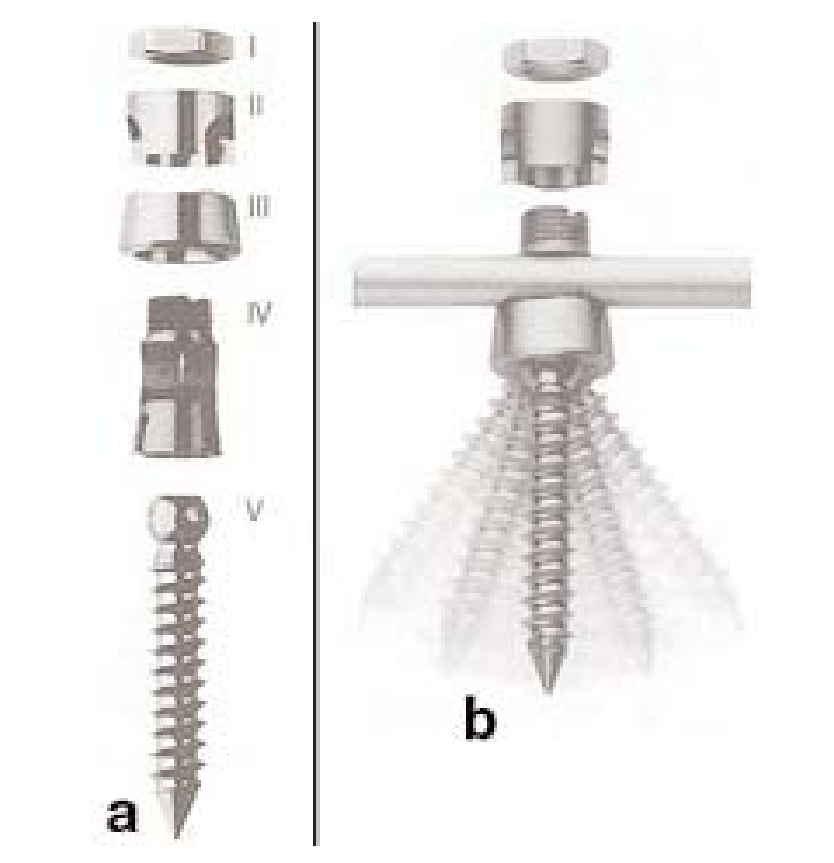

Fig. 8. Example of a polyaxial screw. a: Screw assembly with nut (I); collar (II); locking ring (III); rod-screw connector (IV); and screw (V). b: Angulation around axis of screw. From AO ASIF Principles in Spine Surgery, Aebi, et al., p 184, 1998; reprinted with permission from Springer-Verlag.

sive techniques are to achieve the original aims with shorter recovery time.

\section{References}

1. Birch JG, Herring JA, Roach JW, et al: Cotrel-Dubousset instrumentation in idiopathic scoliosis. Clin Orthop 227: 24-29, 1988

2. Bischoff R, Bennett JT, Stuecker R, et al: The use of Texas Scottish-Rite instrumentation in idiopathic scoliosis. A preliminary report. Spine 18:2452-2456, 1993

3. Cotrel Y, Dubousset J, Guillaumat M: New universal instrumentation in spinal surgery. Clin Orthop 227:10-23, 1988

4. Cotrel Y, Dubousset J: [A new technique for segmental spinal osteosynthesis using the posterior approach.] Rev Chir Orthop Reparatrice Appar Mot 70:489-494, 1984 (Fr)

5. Das K, Rothberg M: Thorascopic surgery: historical perspectives. Neurosurg Focus 9 (4): Article 10, 2000

6. Dickson JH, Harrington PR: The evolution of the Harrington instrumentation technique in scoliosis. J Bone Joint Surg Am 55:993-1002, 1973

7. Dwyer AF, Newton NC, Sherwood AA: An anterior approach to scoliosis. A preliminary report. Clin Orthop 62:192-202, 1969

8. Haas SL: Spastic scoliosis and obliquity of the pelvis. J Bone Joint Surg 24:774-780, 1942

9. Hadra BE: The classic: wiring of the vertebrae as a means of immobilization in fracture and Potts disease. Berthold E Hadra. Med Times and Register, Vol 22, May 23, 1891. Clin Orthop 112:4-8, 1975

10. Hall JE: Spinal surgery before and after Paul Harrington. Spine 23:1356-1361, 1998
11. Harrington PR: Treatment of scoliosis: correction and internal fixation by spine instrumentation. J Bone Joint Surg Am 44: 591-610, 1962

12. Harrington PR: The history and development of Harrington instrumentation. by Paul R. Harrington, 1973. Clin Orthop 227: 3-5, 1988

13. Hibbs RA: A report of fifty-nine cases of scoliosis treated by the fusion operation. J Bone Joint Surg 6:3-34, 1924

14. Howorth MB: Evolution of spinal fusion. Ann Surg 117: 278-289, 1943

15. Kaneda K, Shono Y, Satoh S, et al: New anterior instrumentation for the management of thoracolumbar and lumbar scoliosis. Application of the Kaneda two-rod system. Spine 21: 1250-1262, 1996

16. Kostuik JP: Adult scoliosis, in Rothman RH, Simeone FA (eds): The Spine, ed 3. Philadelphia: WB Saunders, 1992, pp 879-911

17. Lange F: The classic. Support for the spondylitic spine by means of buried steel bars, attached to the vertebrae. By Fritz Lange. 1910. Clin Orthop 203:3-6, 1986

18. Laxer E: A further development in spinal instrumentation. Technical Commission for Spinal Surgery of the ASIF. Eur Spine J 3:347-352, 1994

19. Liljenqvist U, Lepsien U, Hackenberg L, et al: Comparative analysis of pedicle screw and hook instrumentation in posterior correction and fusion of idiopathic thoracic scoliosis. Eur Spine J 11:336-343, 2002

20. Luque ER: Segmental spinal instrumentation for correction of scoliosis. Clin Orthop 163:192-198, 1982

21. McAfee PC, Regan JR, Zdeblick T, et al: The incidence of complications in endoscopic anterior thoracolumbar spinal reconstructive surgery. A prospective multicenter study comprising the first 100 consecutive cases. Spine 20:1624-1632, 1995

22. Moe JH: Modern concepts of treatment of spinal deformities in children and adults. Clin Orthop 150:137-153, 1980

23. Moe JH: A critical analysis of methods of fusion for scoliosis An evaluation in two hundred and sixty-six patients. J Bone Joint Surg Am 40:529-554, 1958

24. Moe JH, Purcell GA, Bradford DS: Zielke instrumentation (VDS) for the correction of spinal curvature. Analysis of results in 66 patients. Clin Orthop 180:133-153, 1983

25. Moen KY, Nachemson AL: Treatment of scoliosis. An historical perspective. Spine 24:2570-2575, 1999

26. Risser JC: Treatment of scoliosis during the past 50 years. Clin Orthop 44:109-113, 1966

27. Wilber RG, Thompson GH, Shaffer JW, et al: Postoperative neurological deficits in segmental spinal instrumentation. A study using spinal cord monitoring. J Bone Joint Surg Am 66:1178, 1984

28. Winter RB, Lonstein JE: Juvenile and adolescent scoliosis, in Rothman RH, Simeone FA (eds): The Spine, ed 3. Philadelphia: WB Saunders, 1992, pp 373-430

29. Zielke K, Stunkat R, Beaujean F: [Ventrale derotationsspondylodesis. (author's transl)] Arch Orthop Unfallchir 85: 257-277, 1976

Manuscript received November 21, 2002.

Accepted in final form December 23, 2002.

Address reprint requests to: Kaushik Das, M.D., Department of Neurosurgery, New York Medical College, Saint Vincent's Hospital, 153 West 11th Street, Suite NR 809, New York, NY 10011. email: kdas25@hotmail.com. 